\author{
Shahin Sultana ${ }^{1 *}$, Mehedi Mannan², Md. Jaynal Abedin², Zahidul Islam¹, Husna Parvin \\ Nur' ${ }^{1}$, Purabi Rani Samaddar ${ }^{1}$ \\ ${ }^{1}$ Fiber \& Polymer Research Division, BCSIR Laboratories Dhaka, Bangladesh Council of \\ Scientific and Industrial Research (BCSIR), Dhaka-1205, Bangladesh \\ ${ }^{2}$ Department of Chemistry, Eden Mohilla College, Dhaka, Bangladesh \\ *shasultana@gmail.com
}

\title{
PHYSICO-MECHANICAL AND THERMAL PROPERTIES OF THERMOPLASTIC POLY(VINYL ALCOHOL) MODIFIED THERMOSETTING UREA FORMALDEHYDE RESIN
}

\begin{abstract}
Urea formaldehyde (UF) resins are brittle and to improve their tensile properties poly(vinyl alcohol) (PVA) has been used to modify the UF resin. An easy improved procedure was developed to make PVA modified UF resin on the basis of conventional synthesis of UF resin. Prepolymer of UF was mixed with different weight percentages of PVA (1-5\%) to synthesize modified UF resin which can be used to make adhesive for forest products. Both UF and modified UF resins were characterized by FTIR, physico-mechanical and thermal properties analyses. Modified UF resin containing 2 wt. \% PVA exhibited better results than the UF.
\end{abstract}

Keywords: Modified urea formaldehyde resin; polyvinyl alcohol; thermal and tensile properties

\section{INTRODUCTION}

Urea formaldehyde (UF) resins are thermosetting polymers which are widely used in particleboard, medium density fiber board, interior plywood manufacturing, finishes and molded objects etc [1-4]. These are amino plastic resins which have a countless variety of condensed structures under various reaction conditions even though they are a chemical product from the reaction of two simple monomers: urea and formaldehyde [1]. They have many advantages, such as high reactivity, colorless glue line, good performance, easy processing and low cost raw materials [2-4]. UF resins are important as adhesive for wood industry during the past century due to their attractive properties at reasonable price, accounting for approximately $60 \%$ of the wood adhesive market [3]. However, they have drawback such as formaldehyde emissions and the brittleness of cured UF resin during the use of UF-bonded panels. These disadvantages of unmodified resins prevented them from achieving very wide usage which can be reduced by modification of UF resins [3-4]. Bio-oil modified UF resin showed improved performance by reducing formaldehyde emissions and improving thermal stability [3]. Polydimethylsiloxanes with different functional groups were 
successfully encapsulated in UF microcapsules for self-healing applications [5]. Bio-based dialdehyde starch (DAS) was chemically introduced into the melamine-urea-formaldehyde (MUF) resin by in situ polymerization between the aldehyde group in the DAS and the amino group and hydroxymethyl group in the resin to improve the strength of MUF resin [6]. Polyamine modified UF resins offers promise for improving the durability and stability of UF bonded wood products by decreasing the internal stress developed during resin cure and by improving the ability of the cured resin to withstand cyclic stresses [7]. Use of the modified starch as an alternative biobased binder for formaldehyde based resins has shown increased particleboard performance [8]. A multitude of pathways have been explored for the improvement of UF resins behavior relating either to their synthesis procedure or application parameters during panel manufacture that manifest the advantageous properties and improved bonding ability of the innovative UF resin [9]. Thermoset epoxy resins can be toughened successfully by blending a small amount (about $10-15 \%$ by weight and having size 0.1 to 5 $\mathrm{mm}$ ) of liquid rubber or by incorporating the preformed rubbery particles directly [10]. There are many different chemical reactions have been published for the modification of thermoset resin. Many research works have been done to reduce formaldehyde emissions and to reduce brittleness of thermoset resins by the incorporation of different types of modifiers in the cured thermoset resin matrix. Low molar ratio (LMR) UF resins showed poor adhesion in woodbased composite panels due to the presence of inherent crystalline domains, modified cellulose nanomaterials (CNMs) such as TEMPO-oxidized cellulose nanofibrils (TEMPOCNFs) can prevent the formation of crystalline domains in LMR UF resins [11]. Oxidized starch (OS) modified UF resin adhesives using blocked pMDI as a cross-linker has been prepared and characterized for plywood and improved performance showed by the modified UF resin with $10 \%$ OS [12]. UF resins were modified with different amounts of almond shells and the results indicated that the optimal addition of almond shells is 3 wt \% which can significantly reduce the formaldehyde emission and increase wet shear strength and thermal stability of the urea formaldehyde resin adhesive [13]. The effects of $\mathrm{CaCO}_{3}$ on the physical and chemical properties of the UF resin has been investigated and reported that UF resin modified with $2 \%$ of $\mathrm{CaCO}_{3}$ showed the improved properties than neat UF resin [14]. UF resins were successfully modified using nanocellulose with an additive concentration of $3 \%$ and the results showed that nanocellulose addition enhanced the resin properties, such as shorter gelation time, faster curing rates at low activation energy, higher tensile shear strength (TSS), and lower formaldehyde emission (FE), compared to those of neat resins [15]. The loading of pristine nanoclay (PNC) and modified nanoclay (MNC) into UF resins improved the adhesion and reduced the formaldehyde emission of UF resins in plywood [16]. UF resin was modified with wood-derived pyrolytic oil (PyO) to form various blending of pyrolytic oil-urea formaldehyde (PyOUF) adhesive and applied to make particleboard with higher property values [17]. The modification of UF resins with 5\% octadecylamine (ODA)modified bentonite (ODA-BNT) nanoclay showed better adhesion strength and lower free formaldehyde compared with neat UF resins [18]. The effect of sodium carboxymethyl cellulose (Na-CMC) added to UF resin on particleboard production has been investigated and the physico-mechanical properties of particleboard showed the best internal bond (IB) strength in the panels with the $20 \% \mathrm{Na}-\mathrm{CMC}$ admixture [19]. Finely ground birch (Betula verrucosa Ehrh.) bark (BB) can be effectively utilized as an eco-friendly additive in UF adhesives to reduce harmful formaldehyde emission up to $14 \%$ for the plywood sample produced with $15 \%$ BB [20]. UF resin (3\%) and ammonium lignosulfonate (ALS) content varying from $6 \%$ to $10 \%$ (based on the dry fibers) was applied to bond high-density dry fiberboard (HDF) panels which exhibited very satisfactory physical and mechanical properties with extremely low formaldehyde content [21]. Phenol-urea-formaldehyde (PUF) resin 
adhesives were modified by adding various ratios of resorcinol to make an easy-cured and high-performance phenol-resorcinol-urea-formaldehyde (PRUF) resin adhesive for wood manufacturing [22]. Better internal bond strengths of particleboards above the requirements of the standard EN 312 were obtained by the incorporation of $10 \%$ of hydroxymethylated thick spent sulfite liquor (TSSLH) with UF resin [23]. Highly branched polyurea (HBPU) was synthesized to modify traditional low molar ratio UF resin and with the addition of HBPU, the formaldehyde emission level of the plywood panels was decreased by more than $30 \%$ [24].Thermoset epoxy resins were modified with thermoplastic polyethersulfone for highperformance applications [25]. Incorporation of plasticizers, like thermoplastic or rubbers to increase the toughness of thermosets is the most promising strategy [26]. Thermoplastic PVA is a water soluble hydrophilic synthetic polymer [27]. Thermoset UF resin is also a waterbased polymer resin which has a wide range of raw materials [28]. Considering the miscibility and compatibility between water based thermoset UF resin and water based thermoplastic PVA resin, the present research was undertaken to investigate the effect of PVA resin on UF resin.

In this research, PVA modified UF resin has been synthesized in both liquid and solid form which can be used to make adhesive for plywood and wood products. To improve the tensile strength of the UF resin and to reduce the free formaldehyde content of UF resin, PVA was used as a modifier at prepolymer stage during the synthesis process of UF resin. FTIR, physico-mechanical and thermal characterization of the synthesized resins were investigated and reported.

\section{MATERIALS AND METHODS}

\section{Materials}

Starting material urea was supplied by BDH Laboratories Ltd., England. Formaldehyde (37\%), polyvinyl alcohol, sodium hydroxide, lactic acid (90\%), methanol, sodium sulphite were collected from Merck, Germany.

\section{Synthesis of urea formaldehyde resin by condensation polymerization method}

The first reaction was carried out following conventional method [29]. Then the reaction parameters of this work were selected from the series of reactions carried out by observing reaction parameters variation effect on fixed molar ratio of urea and formaldehyde following viscosity and FTIR spectroscopic analyses. Sodium hydroxide solution $(\mathrm{NaOH})(1 \mathrm{~N})$ was prepared. Starting material urea and formaldehyde (37\%) were taken into a round bottom flask at 1:2 molar ratios. At first step, hydroxymethylation of urea was done under basic conditions by adding $\mathrm{NaOH}$ solution $(1 \mathrm{~N})$ to make $\mathrm{pH}$ of 7.5-8. The reaction flask was fitted with a condenser and stirred for one hour at room temperature. In the second step, lactic acid solution $(1 \mathrm{~N})$ was prepared. The reaction mixture in the flask was heated at around $98-100^{\circ} \mathrm{C}$. After 20 minutes, it was made acidic $\mathrm{pH} 5.5-6.5$ by the addition of lactic acid $(1 \mathrm{~N})$ and the condensation reaction was carried out for 4-5 hours. After completion of the reaction the reaction mixture was cooled and neutralized by adding sodium hydroxide $(1 \mathrm{~N})$. Water was removed by vacuum distillation and then the solution was casted onto the glass petridish. It was dried in air first and then oven at $60^{\circ} \mathrm{C}$. The dried sheets were taken for further investigation. 


\section{Synthesis of PVA modified urea formaldehyde resin by condensation polymerization method}

At first stage, hydroxymethylation of urea was done according to the same method mentioned above for UF resin synthesis. Aqueous solutions of PVA (1, 2, 3, 4 and 5 wt. \%) on the weight of urea and formaldehyde were prepared separately. At the second stage, after 2 hours of condensation reaction PVA solution was added into the reaction mixture and the condensation reaction was carried out for 2-3 hours at $98-100{ }^{0} \mathrm{C}$. After completion of the reaction, the reaction mixture was cooled, neutralized and water was removed by vacuum distillation. The solution was casted onto the glass petridish and dried in air first and then oven at $60{ }^{\circ} \mathrm{C}$. The resulted sheets were taken for further investigation. PVA modified UF resins were synthesized at different additions of PVA (1-5 wt. \%) by following the same procedure described above. Flow chart of manufacturing process of UF and PVA modified UF is presented in Figure 1.

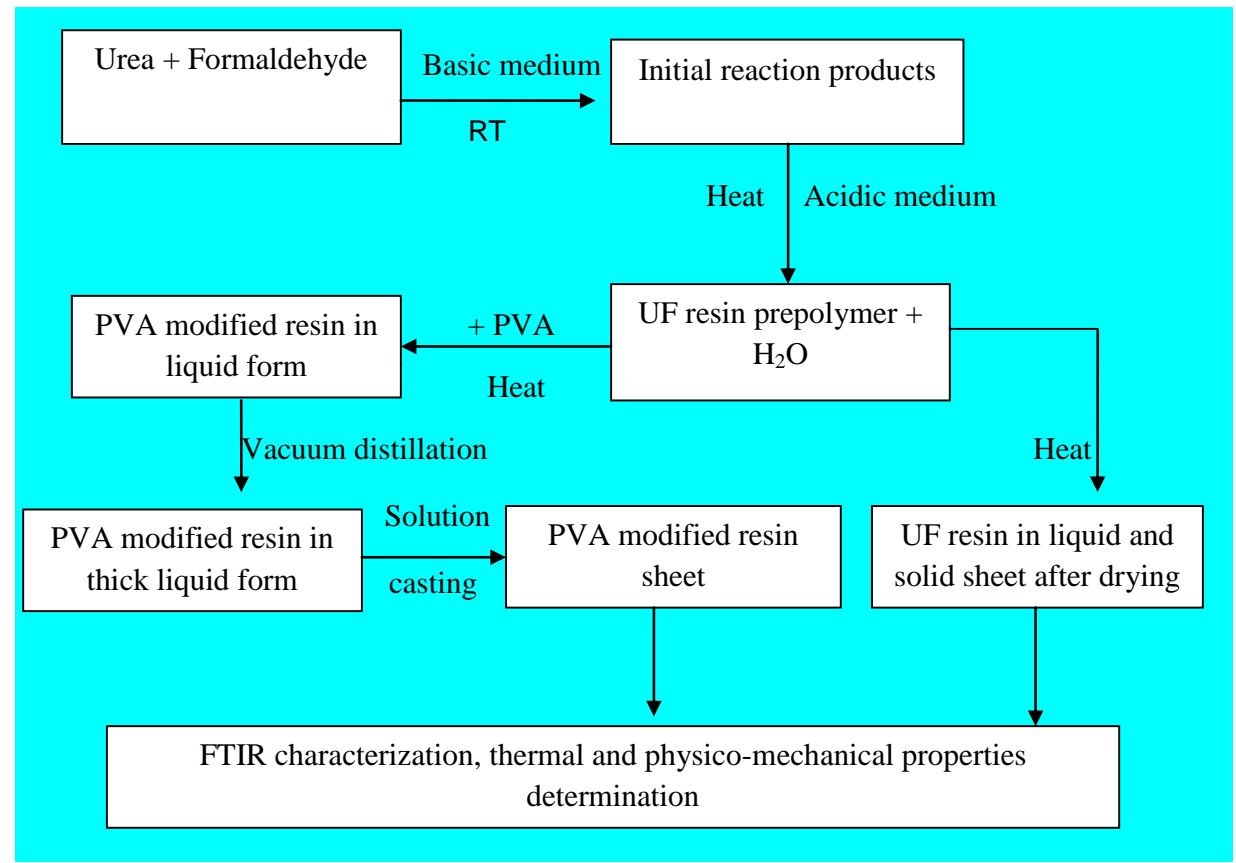

Fig. 1. Manufacturing process of UF resin and PVA modified UF resin

\section{Determination of free formaldehyde content}

Free formaldehyde content of synthesized resins was measured by sodium sulphite method [30]. Sodium sulphite solution was prepared and thymolphthalin indicator was added into it and then neutralized by $1 \mathrm{~N}$ HCL. Synthesized resins sample was added into the sodium sulphite solution and titrated with $1 \mathrm{~N}$ HCL until complete decolourization was obtained. The free formaldehyde $(\%)$ content was calculated from the formula given below:

Free formaldehyde $(\%)=\mathrm{V}$. c. E $/ 10 . \alpha$

Where $\mathrm{V}$ is the volume of HCL $(\mathrm{ml}), \mathrm{c}$ is the concentration of HCL $\left(\mathrm{mol} / \mathrm{dm}^{3}\right), \mathrm{E}$ is the equivalent weight of formaldehyde, and $\alpha$ is the weight of samples (gm).

\section{Determination of physical properties}

The densities and $\mathrm{pH}$ of the synthesized liquid polymers were measured at $24^{\circ} \mathrm{C}$ using Density and Refractometer (DMA 5000, Anton Paar, Austria) and Jenway pH \& conductivity meter, (model-3540, UK) respectively. Miscibility of synthesized liquid polymers in water 
were observed and presented in result and discussion section. Melting points of the synthesized dried solid polymers were determined using dried solid particles of polymer using Gallenkamp melting point apparatus, made in England. The viscosities of liquid polymers were determined using Rotational Viscometer (Anton Paar, Austria) at $24^{\circ} \mathrm{C}$ and presented in result and discussion section.

\section{FTIR spectroscopic characterization of the UF and modified UF resin}

The infrared spectra of the UF, PVA and modified UF were recorded on a FT-IR/NIR Spectrometer (Frontier, Perkin Elmer, USA). The sample pellets for FTIR spectroscopy were prepared by dried powdered samples mixing with dried powdered potassium bromide $(\mathrm{KBr})$ in a small agate mortar pestle. The mixture was taken in a die and pellet was made by applying vacuum pressure. FTIR spectra were obtained by printed form and presented in the result and discussion section.

\section{Mechanical properties of the UF and modified UF resin}

Mechanical properties of the dried sheet of UF and modified UF were performed by universal testing machine (model-Titan 5, James Heal, UK) for all specimens. Tests were performed according to ASTM D 882-02, (Standard Test Method for Tensile Properties of Thin Plastic Sheeting). The speed was $10 \mathrm{~mm} / \mathrm{min}$. The load vs elongation curves were obtained from the instrument and the tensile strength $\left(\sigma_{U T}\right)$ is calculated from the formula below:

Tensile strength, $\sigma_{U T}=\mathrm{W} / \mathrm{A}_{\mathrm{T}}$

Where $\mathrm{W}$ is breaking load and $\mathrm{A}_{\mathrm{T}}$ is the cross sectional area.

\section{Thermal properties of the UF and modified UF resin}

Simultaneous thermal analysis (STA) of the dried UF and modified UF containing 2 wt\% PVA were carried out using STA machine (model no-F 3 Jupiter, NETZSCH, Germany). The temperature range was $30-600^{\circ} \mathrm{C}$, at a heating rate of $10^{\circ} \mathrm{C} /$ min under a constant nitrogen flow rate of $80 \mathrm{ml} / \mathrm{min}$.

\section{RESULTS AND DISCUSSION}

\section{Synthesis of urea formaldehyde resin}

In this work, UF resin was synthesized to make modification on it. The molar ratio of U/F was 0.5 and hydroxymethylation of urea occurred at the first stage. The first stage of condensation polymerization was to prepare monomethylol urea and dimethylol urea by hydroxymethylation of urea as illustrated below. The condensation reaction of monomethylol urea and dimethylol urea was carried out to prepare urea formaldehyde resin at $98-100{ }^{\circ} \mathrm{C}$ for 4-5 hours as illustrated below. Reaction parameters time, temperature and $\mathrm{pH}$ were selected by observing the results of these parameters variation effect on fixed molar ratio of urea and formaldehyde. 


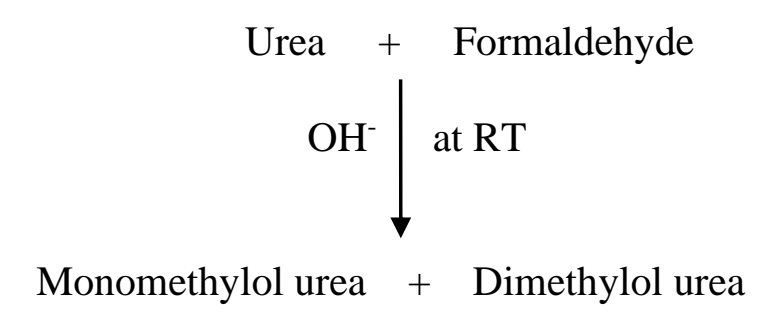

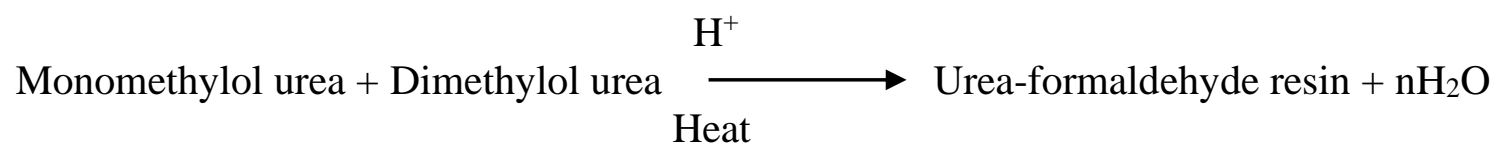

FTIR spectroscopic characterization of UF resin

The synthesized UF resin was characterized by infrared spectroscopic analysis. The FTIR spectrum of UF resin is presented in figure 2 (middle part) and described in the table 1. The IR spectrum shows characteristic bands of N-H stretching at the region of $3316.40 \mathrm{~cm}^{-1}$. The characteristic bands at $1631.14 \mathrm{~cm}^{-1}$ and $1542.31 \mathrm{~cm}^{-1}$ are due to the $\mathrm{C}=\mathrm{O}$ stretching and $\mathrm{N}-\mathrm{H}$ bending vibrations. The spectrum is almost similar to the FTIR spectra of the cured UF resin $[1,12,30]$.

Table 1. FT-IR spectral data of UF resin

\begin{tabular}{cc}
\hline Absorption bands $\left(\mathrm{cm}^{-}\right)$ & Assignment \\
\hline 3316.40 & $\mathrm{~N}-\mathrm{H}$ stretching \\
1631.14 & $\mathrm{C}=\mathrm{O}$ stretching \\
1542.31 & $\mathrm{~N}-\mathrm{H}$ bending \\
1383.34 & $-\mathrm{CH}_{2}$ of methylene bridge \\
1255.81 & $\mathrm{C}-\mathrm{N}$ stretching \\
1194.49 & $\mathrm{C}-\mathrm{O}$ stretching \\
1121.55 & $\mathrm{~N}-\mathrm{CH}_{2}-\mathrm{N}$ asymetric stretching \\
1012.44 & $\mathrm{C}-\mathrm{OH}$ stretching \\
904.56 & $\mathrm{C}-\mathrm{O}-\mathrm{C}$ of ether linkage \\
\hline
\end{tabular}




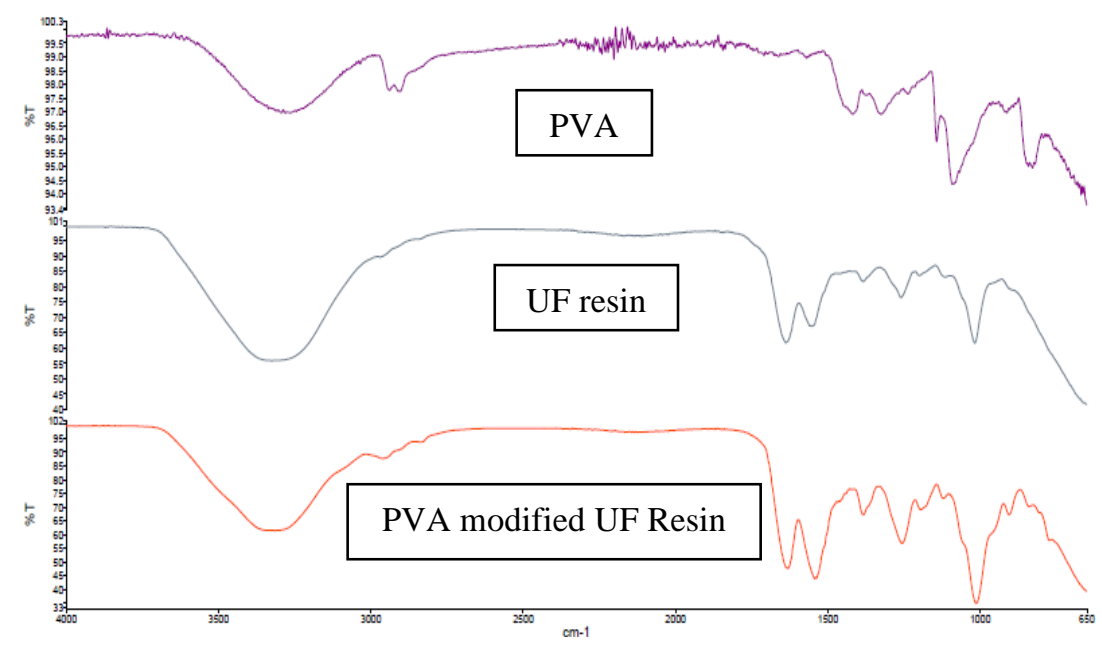

Fig. 2. Infrared spectrum of synthesized PVA modified UF Resin (lower part), synthesized UF resin (middle part) and PVA (upper part) respectively

Synthesis of PVA modified UF resin

The modification of UF resin was done during the second stage of UF resin synthesis after 2 hours. PVA was added during the condensation reaction and at this stage prepolymer of UF was reacted with PVA. The condensation reaction between prepolymer of UF and PVA was continued for 2-3 hours to prepare PVA modified UF resin as illustrated below. Modification of UF resins were carried out at different additions of PVA (1-5 wt \%) to find out the effect of addition amount of PVA on the properties of resins and the selected addition of PVA was found as $2 \mathrm{wt} \%$ by formaldehyde emission and tensile strength. The optimal addition amount of almond shells in UF resin is found as $3 \mathrm{wt} \%$ by formaldehyde emission and wet shear strength [13].

$$
\begin{aligned}
& \mathrm{H}^{+}, 2 \text { hours } \\
& \text { Monomethylol urea }+ \text { Dimethylol urea } \longrightarrow \text { Prepolymer of UF resin }+\mathrm{nH}_{2} \mathrm{O} \\
& 98-100^{\circ} \mathrm{C} \\
& \mathrm{H}^{+}, 2-3 \text { hours }
\end{aligned}
$$

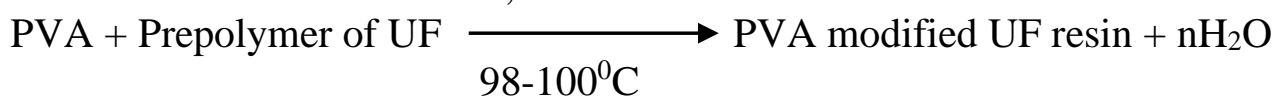

\section{FT-IR spectroscopic characterization of modified UF resin}

The PVA modified UF resin (containing 2 wt\% PVA) was characterized by FTIR spectroscopic analysis. The FTIR spectrum of PVA and PVA modified UF resin are shown in figure 2 (upper and lower part respectively) and described in table 2-3. The FTIR spectrum of PVA modified UF resin (figure 2) shows the characteristic bands of $\mathrm{N}-\mathrm{H}$ and $\mathrm{O}-\mathrm{H}$ is overlapped and broadened at the region of $3328.25 \mathrm{~cm}^{-1}$. Other position of bands were shifted 
in PVA modified UF resin than UF resin which may be due to changes in the polarity of bonds. These observations indicated that structural changes occurred in modified UF resin and PVA structures were introduced into UF resin during condensation reaction.

Table 2. FT-IR spectral data of polyvinyl alcohol

\begin{tabular}{|l|l|}
\hline Absorption bands $\left(\mathrm{cm}^{-}\right)$ & Assignment \\
\hline 3281 & O-H stretching \\
\hline 2905 & $-\mathrm{CH}$ stretching \\
\hline 1420 & $\mathrm{C}=\mathrm{O}$ bending \\
\hline 1323 & $\mathrm{C}=\mathrm{O}$ stretching \\
\hline 1092 & $-\mathrm{CH}_{2}$ group \\
\hline
\end{tabular}

Table 3. FTIR spectral data of PVA modified UF resin

\begin{tabular}{|l|l|}
\hline Absorption bands $\left(\mathrm{cm}^{-}\right)$ & Assignment \\
\hline 3328.25 & $\mathrm{~N}-\mathrm{H}$ and $\mathrm{O}-\mathrm{H}$ stretching \\
\hline 1637.99 & $\mathrm{C}=\mathrm{O}$ stretching \\
\hline 1554.78 & $\mathrm{~N}-\mathrm{H}$ bending \\
\hline 1384.42 & $-\mathrm{CH}_{2}$ of methylene bridge \\
\hline 1122.50 & $\mathrm{~N}-\mathrm{CH}_{2}-\mathrm{N}$ asymetric stretching \\
\hline 1017.20 & $\mathrm{C}-\mathrm{OH}$ stretching \\
\hline
\end{tabular}

Physical properties of synthesized UF resin and PVA modified UF resin

Some physical properties of synthesized UF resin and PVA modified UF resin were measured and presented in table 4. Free formaldehyde content of PVA modified UF resin decreases with increasing PVA content. Similar observations were reported in biooil modified UF resin and melamine, ethylene urea, hexamethylenetetramine (HMTA) modified UF resin respectively $[3,30]$.

Table 4. Physical properties of UF resin and PVA modified UF resin

\begin{tabular}{|c|c|c|c|c|c|c|}
\hline $\begin{array}{l}\text { Name of synthesized } \\
\text { polymer }\end{array}$ & $\begin{array}{l}\text { Solubility } \\
\text { in water at } \\
\text { liquid state } \\
\text { of polymer }\end{array}$ & $\begin{array}{l}\mathrm{pH} \text { at } \\
24^{\circ} \mathrm{C}\end{array}$ & $\begin{array}{l}\text { Density } \\
(\mathrm{g} / \mathrm{mL}) \\
\text { at } 24^{0} \mathrm{C}\end{array}$ & $\begin{array}{l}\text { Viscosity } \\
\text { at } \quad 24^{0} \mathrm{C} \\
(\mathrm{mPa} . \mathrm{s})\end{array}$ & $\begin{array}{l}\text { Free } \\
\text { formaldehyde } \\
\text { content }(\%)\end{array}$ & $\begin{array}{l}\text { Melting } \\
\text { Point }\end{array}$ \\
\hline UF resin & Soluble & 6.11 & 1.03 & 85.23 & 12 & \multirow{6}{*}{ 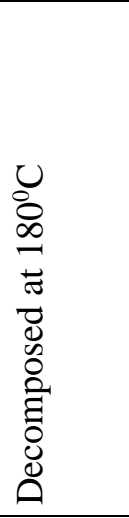 } \\
\hline 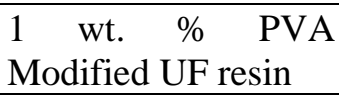 & Soluble & 6.83 & 1.05 & 98.36 & 6 & \\
\hline $\begin{array}{lcc}2 & \text { wt. } \% & \text { PVA } \\
\text { Modified UF resin }\end{array}$ & Soluble & 6.79 & 1.09 & 109.07 & 6 & \\
\hline $\begin{array}{l}3 \text { wt. } \% \text { PVA } \\
\text { Modified UF resin }\end{array}$ & Soluble & 6.75 & 1.14 & 110.33 & 5 & \\
\hline $\begin{array}{l}4 \text { wt. } \% \\
\text { Modified UF resin }\end{array}$ & Soluble & 6.30 & 1.20 & 111.72 & 5 & \\
\hline $\begin{array}{lll}5 & \text { wt. } \% & \text { PVA } \\
\text { Modified UF resin }\end{array}$ & Soluble & 6.15 & 1.27 & 115.11 & 4 & \\
\hline
\end{tabular}




\section{Mechanical properties of UF and PVA modified UF resin}

Mechanical properties such as tensile strength and elongation at break (\%) of all synthesized polymers were conducted by UTM. The tensile strength of the UF and modified UF resin with 1-5 wt \% PVA are presented in figure 3. Tensile strength of $100 \%$ UF resin and $100 \% \mathrm{PVA}$ is $0.13 \mathrm{MPa}$ and $0.17 \mathrm{MPa}$ respectively. It is found that tensile strengths of the UF resin increase with its modification with PVA. It is also found that the tensile strength of the modified UF is higher at $2 \mathrm{wt} \%$ PVA loading and then decreases with increasing PVA content. Similar trend of tensile strength was observed in modified melamine formaldehyde resin and modified epoxy resin [31-32]. The addition of PVA improved the tensile strength performance of the PVA modified UF resin due to the form of physical crosslinking between the resin with flexible chain of PVA, so PVA shared part of the stress uniformly when subjected to external forces that increased the tensile strength of modified resin. At higher loading of PVA after $2 \mathrm{wt} \%$, the tensile strength of modified resin decreases with increasing of PVA due to critical content of PVA. This critical loading is mainly because at higher loading the distance between PVA becomes so small that they tend to stack together due to the van der Waals force that leading to non-uniform stress distribution between the resin and PVA [33]. Elongation at break of the UF resin and modified UF resin are presented in figure 4. Elongation at break of $100 \%$ UF resin is $271.69 \%$ and $100 \%$ PVA is $16.92 \%$. It is observed from the figure that elongation at break of $100 \%$ UF resin decreases than modified UF resin. It is also observed that elongation at break of modified UF resin increases with increasing PVA content. The toughness or ductility of the modified UF resins decreases than UF resin caused by uncured state of UF. It is also observed that toughness or ductility property of modified UF resin increases with increasing of PVA content. UF resin was significantly toughened by polyurethane (PU) addition and the elongation at break of PU modified UF resin increased with increasing PU content [34].

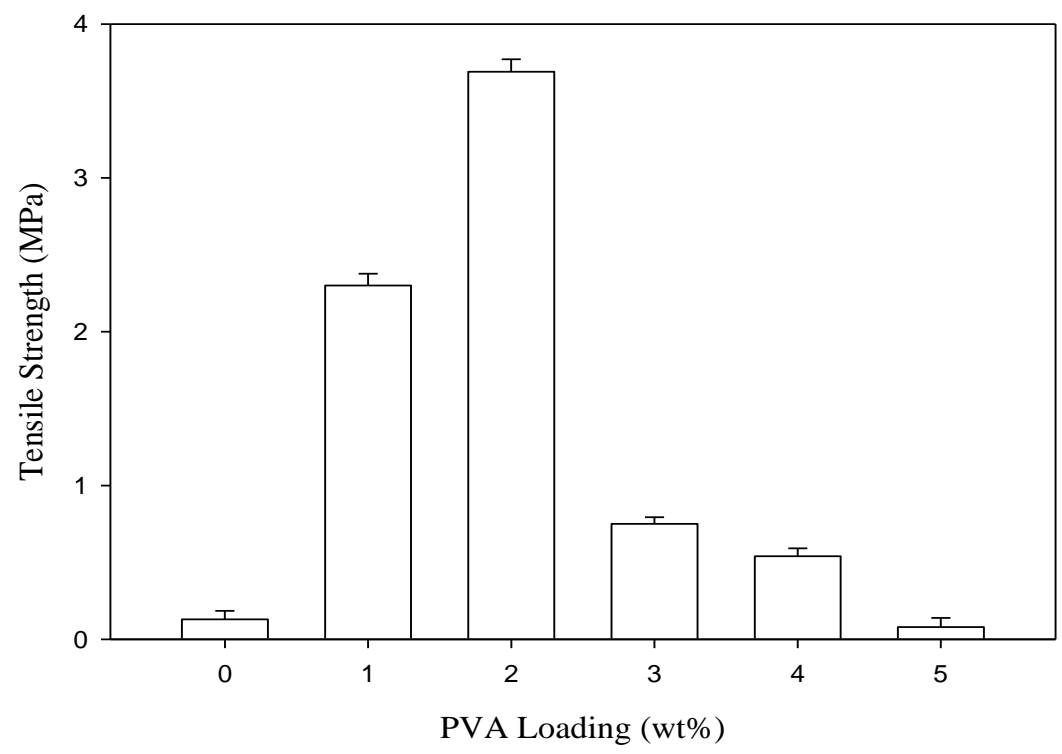

Fig. 3. Tensile strength vs PVA wt. \% of UF resin 


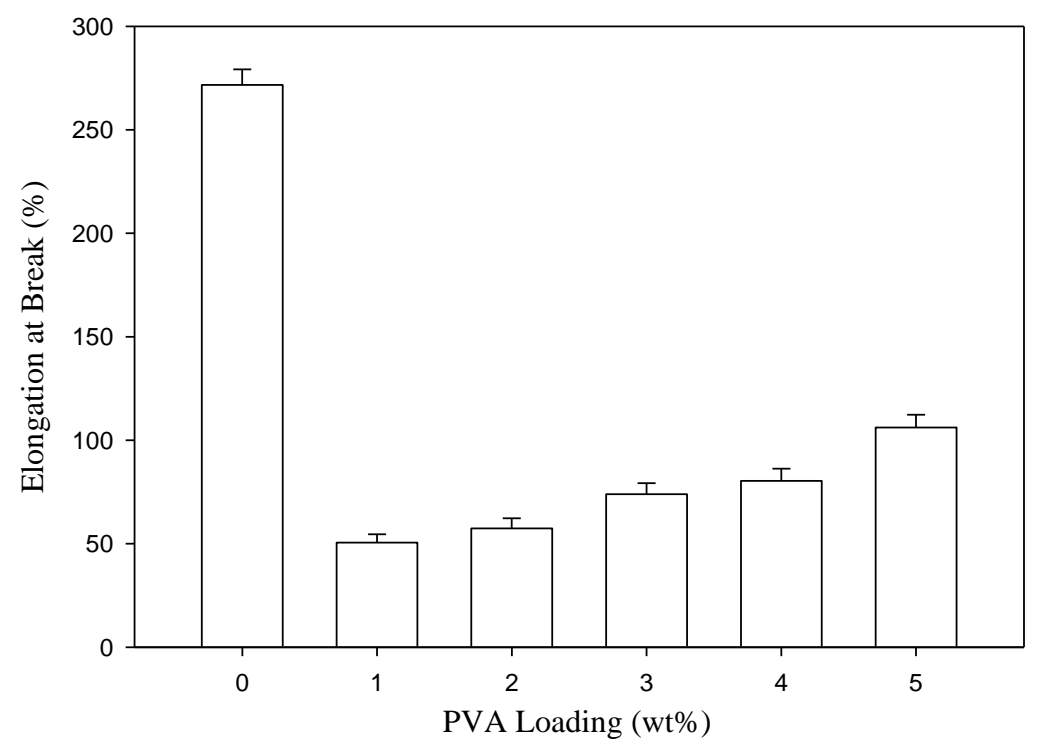

Fig. 4. Elongation at break vs PVA wt. \% of UF resin

\section{Thermal properties of UF resin and PVA modified UF resin}

Thermal analyses of UF resin and modified UF resin having 2 wt. \% PVA were conducted by STA and the results are presented in the figure 5-6 and table 5 respectively. The thermogravimetric analysis (TGA) and differential scanning calorimetric (DSC) results of UF resin and modified UF resin are expressed in table 5. Temperature of initial mass loss $\left(\mathrm{T}_{\mathrm{i}}{ }^{\circ} \mathrm{C}\right)$ and temperature of maximum mass loss $\left(\mathrm{T}_{\max }{ }^{\circ} \mathrm{C}\right)$ with percentages of mass loss and percentage of residue with temperature are shown in table 5. From this comparative observation it is clear that modified UF is thermally more stable than UF. Almost similar TGA is found for neat UF resin but modification of UF with calcium carbonate has no significant effect on the thermal stability of UF resins [14].

The main characteristics parameters such as glass transition temperature $(\mathrm{Tg})$ and melting point (Tm) of UF and modified UF is obtained from DSC analysis (figure 5-6). It is found from the figure 5-6 that the first physically change at differential peak temperature $\left(\mathrm{DTp}_{1}\right)$ and second physically change at differential peak temperature (DTp $)$ are almost same for both UF and modified UF resins (table 5). The glass transition temperature (Tg) and melting point temperature (Tm) of UF may be $172.4^{\circ} \mathrm{C}$ and $282.4^{\circ} \mathrm{C}$ where as for modified UF may be $169.7^{\circ} \mathrm{C}$ and $279.6^{\circ} \mathrm{C}$ respectively.

Table 5. STA data of UF resin and PVA modified UF resin

\begin{tabular}{|c|c|c|c|c|c|}
\hline $\begin{array}{c}\text { Sample } \\
\text { name }\end{array}$ & $\begin{array}{c}\mathrm{T}_{\mathrm{i}}{ }^{\circ} \mathrm{C} \text { and } \\
\text { mass loss }(\%)\end{array}$ & $\begin{array}{c}\mathrm{T}_{\max }{ }^{\circ} \mathrm{C} \text { and } \\
\text { mass loss } \\
(\%)\end{array}$ & $\begin{array}{c}\text { Residue (\%) } \\
\text { at } \mathrm{T}{ }^{\circ} \mathrm{C}\end{array}$ & $\mathrm{DTp}_{1}$ & $\mathrm{DTp}_{2}$ \\
\hline UF resin & $97.7^{\circ} \mathrm{C}$ & $355.9^{\circ} \mathrm{C}$ & 20.04 & $172.4^{\circ} \mathrm{C}$ & $282.4^{\circ} \mathrm{C}$ \\
\hline $\begin{array}{c}0.6 \\
\text { Modified }\end{array}$ & $99.26^{\circ} \mathrm{C}$ & $375.3^{\circ} \mathrm{C}$ & 15.76 at & $169.7^{\circ} \mathrm{C}$ & $279.6^{\circ} \mathrm{C}$ \\
UF resin & 0.74 & 76.45 & $647.1^{\circ} \mathrm{C}$ & & \\
having 2 & & & & & \\
wt.\% PVA & & & & & \\
\hline
\end{tabular}




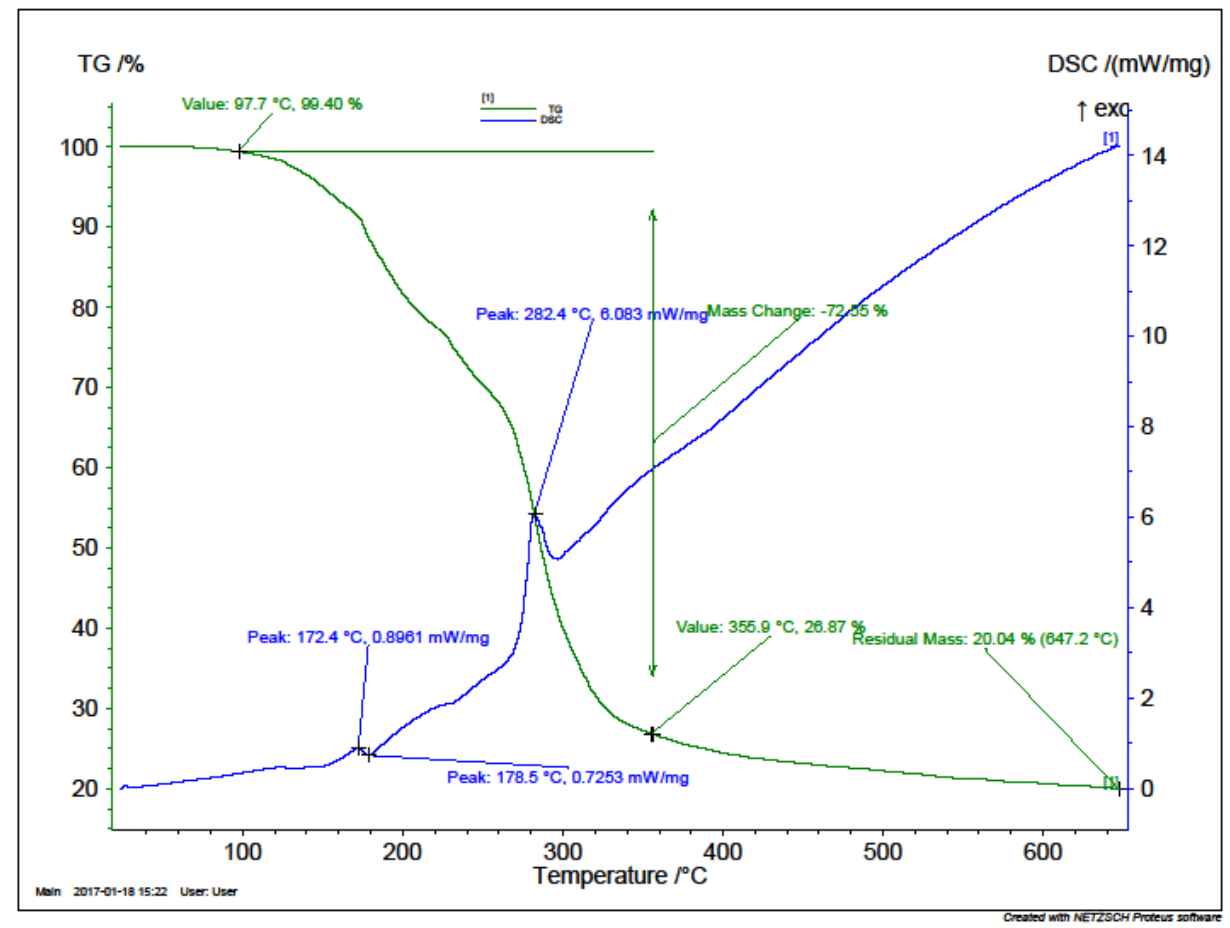

Fig. 5. TGA and DSC curve of UF resin by STA analysis

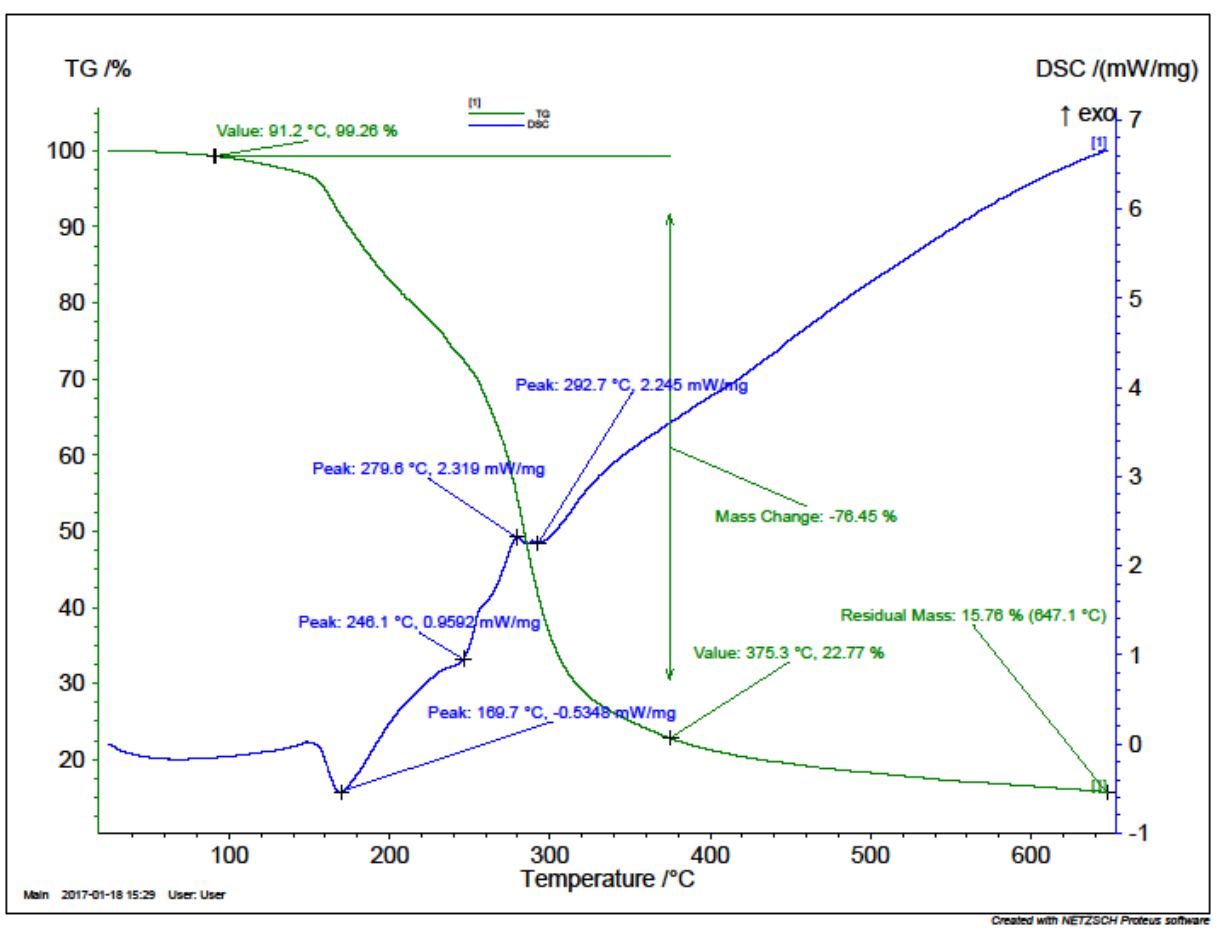

Fig. 6. TGA and DSC curve of modified UF resin having 2 wt. \% PVA 


\section{SUMMARY}

Synthesis of UF resin and its modification by PVA was successfully carried out. FTIR spectroscopic analyses showed the evidence of the structure of PVA modified UF resin. The amount of free formaldehyde of PVA modified UF resin decreased than neat UF resin and it also decreases with increasing of PVA content in the UF resin.Tensile strength of modified UF resin is higher than that of unmodified UF resin and the highest tensile strength obtained for $2 \mathrm{wt} \%$ PVA loaded UF resin. So it can be concluded that addition of PVA can strengthen UF resin by improving its tensile strength and reducing brittleness. Thermo gravimetric analysis also indicated that PVA modified UF is thermally more stable than unmodified UF resin. Therefore, PVA is a potential modifier for UF resin to improve its performance. So, it can be said that PVA modified UF resin will improve the performance of this resin for use as adhesive for plywood and for wood products.

\section{ACKNOWLEDGEMENTS}

The authors would like to express their sincere gratitude to the authority of Bangladesh Council of Scientific and Industrial Research (BCSIR) for providing laboratory facilities.

\section{REFERENCES}

1. Liu M., Thirumalai R.V.K.G., Wu Y., Wan H.: Characterization of the crystalline regions of cured urea formaldehyde resin. RSC Advances 7 (2017) 49536-49541.

2. Solt P., Konnerth J., Altmutter W.G., Kantner W., Moser J., Mitter R., Herwijnen H. W.G.v.: Technological performance of formaldehyde-free adhesive alternatives for particleboard industry. International Journal of Adhesion and Adhesives 94 (2019) 99-131.

3. Li B., Zhang J., Ren X., Chang J., Gou J.: Preparation and Characterization of Bio-Oil Modified Urea-Formaldehyde Wood Adhesives. BioResources 9(3) (2014) 5125-5133.

4. Pink S., Herwijnen H.W.G., Veigel S., Altmutter W.G., Riegler M.: Urea-formaldehyde microspheres as a potential additive to wood adhesive. Journal of Wood Science 64 (2018) 390397.

5. Ullah H., Azizli K., Man Z.B, Ismail M.B.C.: Synthesis and Characterization of Ureaformaldehyde Microcapsules Containing Functionalized Polydimethylsiloxanes. Procedia Engineering 148 (2016) 168-175.

6. Luo J., Zhang J., Gao Q., Mao A., Li J.: Toughening and Enhancing Melamine-UreaFormaldehyde Resin Properties via in situ Polymerization of Dialdehyde Starch and Microphase Separation. Polymers 11 (2019) 1-18.

7. Ebewele R.O., Myers G.E., River B.H., Koutsky J.A.: Polyamine-Modified Urea-Formaldehyde Resins. I. Synthesis, Structure, and Properties. Journal of Applied Polymer Science 47 (1991) 2997-3012.

8. Kariuki S.W., Wachira J., Kawira M., Murithi G.: Formaldehyde Use and Alternative Biobased Binders for Particleboard Formulation: A Review. Journal of Chemistry (2019) 1-12. Article ID 5256897.

9. Zorba T., Papadopoulou E., Hatjiissaak A., Paraskevopoulos K.M., Chrissafis K.: Urea formaldehyde resins characterized by thermal analysis and ftir method. Journal of Thermal Analysis and Calorimetry 92 (2008) 29-33. 
10. Ratna D., Banthia A.K.: Rubber Toughened Epoxy. Macromolecular Research 12(1) (2004) 1121.

11. Seongsu P., Byung D.P.: Crystallinity of Low Molar Ratio Urea-Formaldehyde Resins Modified with Cellulose Nanomaterials. Journal of the Korean Wood Science and Technology 49(2) (2021)169-180.

12. Lubis M.A.R., Park B.D.: Modification of urea-formaldehyde resin adhesives with oxidized starch using blocked pMDI for plywood. Journal of Adhesion Science and Technology (2018). DOI: $10.1080 / 01694243.2018 .1511075$

13. Chen K., Cheng X., Chen Y., Qi J., Xie J., Huang X., Jiang Y., Xiao H.: Thermal Degradation Kinetics of Urea-Formaldehyde Resins Modified by Almond Shells. ACS Omega 6 (2021) 25702-25709.

14. Lu L., Wang Y., Li T., Wang S., Yang S., Qing Y., Li X., Wu Y., Liu M.: Calcium carbonate modified urea-formaldehyde resin adhesive for strength enhanced medium density fiberboard production. RSC Advances 11 (2021) 25010.

15. Wibowoa E.S., Lubis M.A.R., Park B.D.: In-situ modification of low molar ratio ureaformaldehyde resins with cellulose nanofibrils for plywood. Journal of Adhesion Science and Technology (2021).

16. Yadava S.M., Lubis M.A.R., Park B.D.: Modification of nanoclay with different methods and its application in ureaformaldehyde bonded plywood panels. Wood Material Science \& Engineering (2021).

17. Adegoke O.A., Ogunsanwo O.Y., Olaoye K.O.: Modification of Urea Formaldehyde Resin with Pyrolytic Oil on Particleboard. Journal of Forest and Environmental Science 36 (3) (2020) 219224.

18. Lubis M.A.R., Park B.D.: Enhancing the performance of low molar ratio urea-formaldehyde resin adhesives via in-situ modification with intercalated nanoclay. The Journal of Adhesion 97(14) (2020) 1271-1290.

19. İstek A., Biçer A., Özlüsoylu I.: Effect of sodium carboxymethyl cellulose (Na-CMC) added to urea-formaldehyde resin on particleboard properties. Turkish Journal of Agriculture and Forestry 44 (2020) 526-532.

20. Réh R., Krišt’ák L., Sedliacik J., Bekhta P., Božiková M., Kunecová D., Vozárová V., Tudor E.M., Antov P., Savov V.: Utilization of Birch Bark as an Eco-Friendly Filler in UreaFormaldehyde Adhesives for Plywood Manufacturing. Polymers 13 (2021) 511.

21. Antov P., Savov V., Krišsták L., Réh R., Mantanis G.I.: Eco-Friendly, High-Density Fiberboards Bonded with Urea-Formaldehyde and Ammonium Lignosulfonate. Polymers 13 (2021) 220.

22. Li B.P.M.K., Yuan S.Y.T.Q., Du G.B., Sun R.C.: Eco-Friendly Phenol-Urea-Formaldehyde Cocondensed Resin Adhesives Accelerated by Resorcinol for Plywood Manufacturing. ACS Omega 3 (2018) 8521-8528.

23. Ferreira A.M., Pereira J., Almeida M., Ferra J., Paiva N., Martins J., Carvalho L.H., Magalhães F.D.: Effect of spent sulfite liquor on urea-formaldehyde resin performance. Journal of Applied Polymer Science 136(17) (2018) 47389.

24. Jiang S., Hu M., Du G., Duan Z., Zhou X., Li. T.: Highly branched polyurea-enhanced urea formaldehyde resin. ACS Applied Polymer Materials 3 (2021) 1157-1170.

25. Mathis E., Michon M.L., Billaud C., Grau P., Bocahut A., Vergelati C., Long D.R.: Thermoset modified with polyethersulfone: characterization and control of the morphology, Journal of Polymer Science. Part A-1, Polymer Chemistry 58 (8) (2020) 1177-1188. 
26. Acebo C., Ramis X., Serra A.: Improved epoxy thermosets by the use of poly(ethyleneimine) derivatives. Physical Sciences Reviews (2017) 1-31, 20160128.

27. Feldman D.: Poly(vinyl alcohol) nanocomposites: Recent contributions to engineering and medicine. AIMS Materials Science 8(1) (2021) 119-129.

28. Li J., Zhang Y.: Morphology and Crystallinity of Urea-Formaldehyde Resin Adhesives with Different Molar Ratios Polymers 13 (2021) 673.

29. Ohalete M.N., Popoola A.V.: Urea-formaldehyde Resins Synthesis, Modification and Characterization. Journal of Applied Chemistry (IOSR-JAC) 12(8) (2019) 19-25.

30. Jovanovic S.S., Jovanovic V., Konstantinovic S., Markovic G., Cincovic M.M.: Thermal behavior of modified urea-formaldehyde resins. Journal of Thermal Analysis and Calorimetry 104 (2011) $1159-1166$.

31. Chen X., Afreen S., Yu X., Dong C., Kong Q.: Modified melamine-formaldehyde resins improve tensile strength along with antifouling and flame retardancy in impregnation of cellulose paper. RSC Advances 9 (2019) 36788-36795.

32. Balasubramanya P.C., Natarajan K.: Mechanical and Morphological Studies of Modified Epoxy Resin Matrix for Composite Applications. International Journal of Emerging Technology and Advanced Engineering 4(1) (2014) 281-288.

33. Jinhong D., Ming C.H.: The Fabrication, Properties, and Uses of Graphene/Polymer Composites. Macromolecular Chemistry and Physics 213 (2012) 1060-1077.

34. Yuan J., Zhao X., Ye L.: Structure and properties of urea-formaldehyde resin/polyurethane blend prepared via in-situ polymerization. RSC Advances 5 (2015) 53700-53707. 